\title{
SONOMAMMOGRAPHIC EVALUATION OF BREAST MASSES
}

\author{
Vandana Tewari*, Sheela Sharma**, Rahul Ranjan** \\ *Department of Anatomy, Rama Medical College Hospital and Research Centre, Kanpur, UP. \\ **Department of Obstetrics \& Gynaecology, Rama Medical College Hospital and Research Centre, Kanpur, UP. \\ ${ }^{* * *}$ Department of Radiology, Rama Medical College Hospital and Research Centre, Kanpur, UP.
}

\begin{abstract}
Introduction: Sonomammography is an ideal, noninvasive, painless and accurate procedure used to detect and evaluate breast masses. In this study, detection evaluation and characterization of breast masses was done with ultrasound for a period of seven months from March 2017 to September 2017.
\end{abstract}

Material \& Methods: 106 patients from Department of Surgery and Obstetrics \& Gynaecology were screened by clinical and ultrasound examination. Histological confirmation was done by fine needle as piration cytology and excision biopsy.

Results: On examination, the distribution of lesions were fibroadenoma, fibrocystic disease, mastitis, breast cyst, abscess, galactocele, fat necrosis, lipoma, papilloma, invasive ductal carcinoma and invasive lobular carcinoma.

Conclusion: Sonomammography is a powerful tool to evaluate breast masses as it is less affected by tissue density. It improves the visualization of tumours in radio dense breasts and as well as improves the specificity of mammography when used in conjunction.

Keywords: Mammography, fine needle aspiration cytology, fibroadenoma, fibrocystic disease.

\section{INTRODUCTION}

Definitive diagnosis of breast lesions without resort to formal biopsy is highly desirable both for patient and clinicians and thus avoids unnecessary breast surgeries in benign conditions [1]. The failure of mammography as a definitive diagnostic technique is usually due to problems associated with breast density [2] which leads to false positive diagnosis. Meticulous ultrasound including all the four quadrants of breast, nipple areola complex, axilla helps in diagnosing all the breast lesions, focal asymmetric densities and palpable abnormalities with $98 \%$ sensitivity [3], only disadvantage being that early nature of breast malignancy i.e. microcalcification cannot be detected by sonomammography.

\section{MATERIALS AND METHODS}

The present study was conducted in the Department of Radiodiagnosis, Rama Medical College Hospital and Research Centre, Kanpur, Uttar Pradesh, India. Patients under study were referred from Department of Surgery and Obstetrics \& Gynaecology and evaluated by clinical and ultrasound examination.

Patient evaluation was done clinically and by radiological evaluation. Detailed clinical history was taken along with general and local examination. High resolution real time sonography of breast was also done. Patients were divided into different age groups i.e. 10-20, 21-30, 31-40, 41-50, 51-60 and 61-70 years. Lumps was seen in all patients and scanning was done with 7-10n MHZ Transducer on Siemens Accuson X 300 Premium Edition and Voluson P8. Sonographic examination of inner quadrants of breast was done in supine position and outer quadrants was done in decubitus and ipsilateral position with raised

\section{Address for Correspondence:}

Dr Vandana Tewari, Associate Professor, Department of Anatomy, Rama Medical College Hospital and Research Centre, Kanpur, UP, India. Mob: 9839176353 Email: vandanatewari27@yahoo.in 
arms. Color doppler and Power doppler was used to determine vascularity [4]

Histopathological confirmation was done in all patients.

\section{OBSERVATIONS AND RESULTS}

Maximum number of patients with breast masses were seen in the age group 31-40 years followed by 41-50 and $51-60$ years (Fig. 1 ).

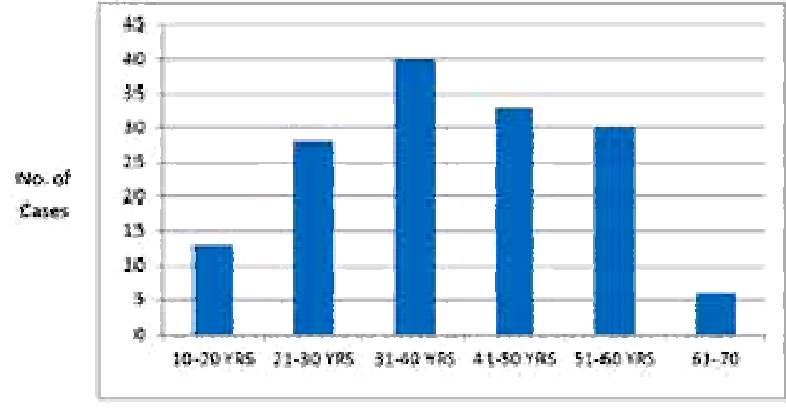

Fig. 1: Bar diagram showing number of cases in different age groups

Lesions of breast were detected in 89 cases, indeterminate in 4 and normal finding on USG was seen in 13 cases. Nature of lesion was divided into various types as observed in ultrasound. Of these maximum cases were of fibroadenoma (28.1\%) followed by fibrocystic disease of breast (21.4\%) (Table 1, Fig. 2-7))

Table 1: Ultrasonic characterization of breast lesions $(n=89)$

\begin{tabular}{|c|c|}
\hline Nature of lesion & No. of cases (\%) \\
\cline { 1 - 1 } Fibroadenoma & $25(28.1)$ \\
\hline Fibrocystic disease of breast. & $19(21.4)$ \\
\hline Mastitis & $10(11.3)$ \\
\hline Breast cyst & $6(6.7)$ \\
\hline Breast abscess & $4(4.4)$ \\
\hline Fat Necrosis & $3(3.3)$ \\
\hline Lipoma & $2(2.2)$ \\
\hline Papilloma & $2(2.2)$ \\
\hline \hline Invasive Ductal Carcinoma & $14(15.8)$ \\
\hline Invasive Lobular Carcinoma & $4(4.6)$ \\
\hline
\end{tabular}

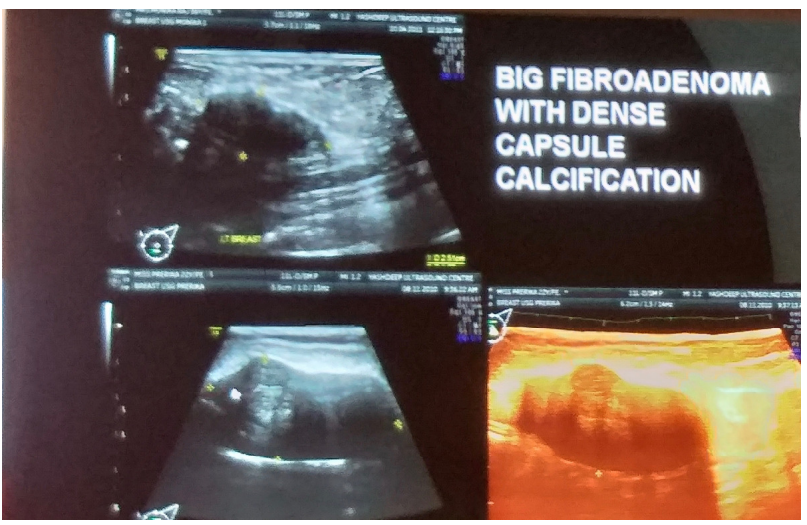

Fig. 2: Fibroadenoma with smooth margin (benign) with regular walls on USG

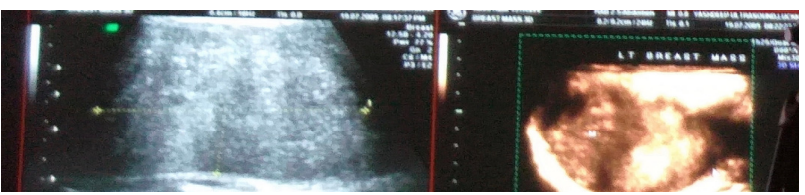

Fig. 3: Big Fibroadenoma with shadowing on USG

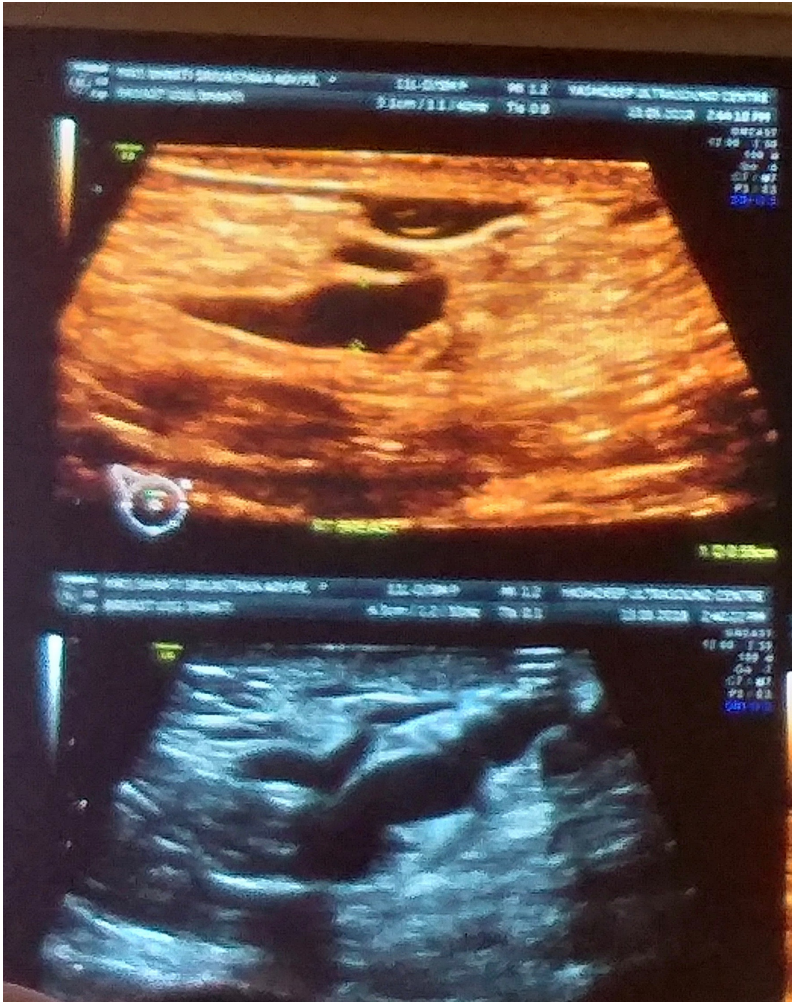

Fig. 4: Breast cyst (anechoic mass with thin walls) on USG 


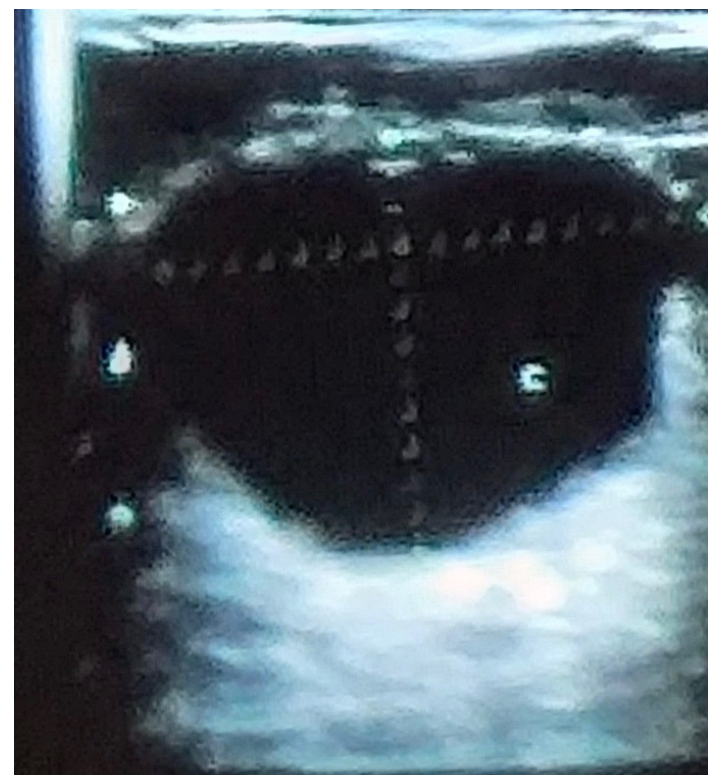

Fig. 5: Duct ectasia with dilated duct and irregular walls on USG

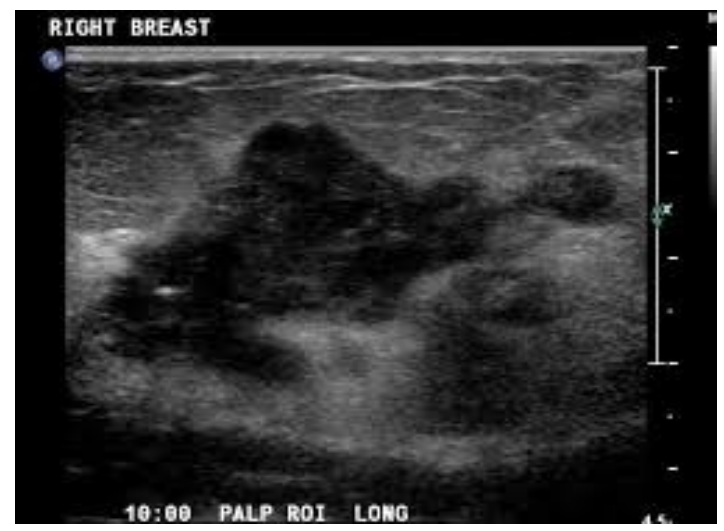

Fig. 6: Intraductal papilloma (small papillomatus growth in the duct) on USG

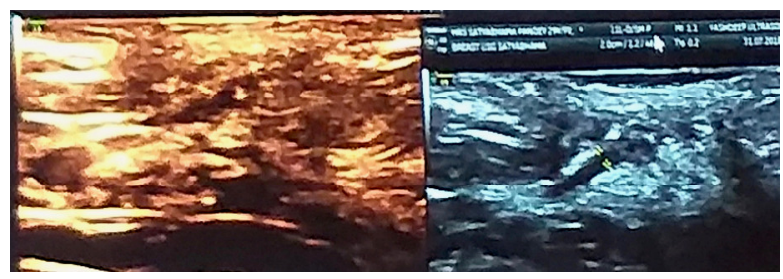

Fig. 7: Invasive lobular carcinoma (big irregular hetero-genous mass distorting the breast architecture)

Histopathological evaluation was also done and the lesions were categorized as benign, indeterminate and malignant of which benign were observed in maximum number of cases (Table 2).
Table 2: Histopathological categorization of lesion detected on USG examination $(n=89)$

\begin{tabular}{|c|c|}
\hline Nature of lesion & No. of cases (\%) \\
\hline Benign & $66(74.15)$ \\
\hline Indeterminate & $4(4.49)$ \\
\hline Malignant & $19(21.32)$ \\
\hline
\end{tabular}

\section{DISCUSSION}

In our study, 106 patients with complaints of breast lumps were assessed. Mostly patients presented with clinical features of heaviness, lumpiness /actual lumps/swelling, pain, nipple discharge or retraction and combination of these complaints. Out of 106 patients, lesions were detected in 91 patients on ultrasound examination, while 11 patients were normal on clinical and ultrasound examination and 4 patients were with undetermined lesions on USG.

Benign breast disease comprised of fibroadenoma, fibrocystic disease, breast abscess, breast cyst, lipoma, trauma and haematoma. In fibrocystic diease, patient presented with pain in both breasts which was continuous /cyclical. USG revealed abundant fibrous tissue and cysts of varying size, thick glands and hypoechoic surrounding gives a mottled and spongy appearance to the breast. It is usually seen in young women. Sometimes found as incidental mass on ultrasound; it is usually homogenous, well defined, hypoechoic, ellipsoid, width more than height and may even show posterior enhancement. It may also present with foci of calcifications within. Fibroadenoma can be multiple / solitary. The calcifications within a fibroadenoma are coarse and may show posterior acoustic shadowing. Complex fibroadenomas have a higher incidence of transformation into breast cancer. On Color doppler evaluation, mostly lesions presented with mild/ absent vascularity $[5,6]$. Cases with breast abscess were seen in lactating females except one which presented post trauma which may be due to infected haematoma. Patients having breast cysts showed either simple or complex cystic features on USG.

On USG, simple cysts presented as completely anechoic lesion, with a thin echogenic capsule, posterior acoustic enhancement, and thin clear edge shadow. Complex cysts showed internal echoes, septations or thick irregular walls. Sometimes, it may appear as hypoechoic or solid echogenic lesion, 
depends on its contents. On Color Doppler, mostly lesions present with increased peripheral vascularity.

Lipomas are fatty tumours in the breast parenchyma and appear uniformly ecogenic to heterogenous or completely anechoic masses. We found well defined oval echogenic mass, mildly compressible on probe pressure and did not show any significant vascularity. Lesions due to trauma or hematoma were found to be varied in appearance, grossly echogenic to completely anechoic in texture with a history of trauma.

Malignant breast lesions presented with irregular mass with heterogenous echoes surrounded by halo retrotumour shadowing in $40 \%$ cases, tumour nidus is small, irregular and poorly reflective, internal echo may be small in sub centimeter tumour, beam attenuation observed in $70 \%$ cases [7].

Characterstic/diagnostic features of malignant masses found were spiculations, angular margins, shadowing, calcifications, branch pattern, microlobulation and duct extension.

Papillomas in the breast may be intracystic or intraductal. They are difficult to differentiate from papillary carcinomas only on sonography and a FNAC/biopsy is required for confirmation. In our study, most of the patients with clinical complaint of bloody nipple discharge were turned out to be intraductal and intracystic papillomas/papillary carcinoma [8]. On USG, it presented as a complex cystic lesion with an intracystic, solid, polypoidal echogenic mass of varying sizes. On CD \& PD, lesions presented with increased vascularity within solid echogenic component. Invasive ductal carcinoma presented with irregular ill-defined micro lobulated heterogenous mass with indistinct margins. These lesions were taller than their width in dimensions [9]. Invasive lobular carcinoma is the second most common breast malignancy and maybe seen in elderly women. Appearances are variable ranging from architectural distortion with shadowing. In our scans, ill-defined heterogenous hypoechoic lesions with areas of architectural distortions were observed.

Fat necrosis is a common entity. However, may pose difficulty to clinicians and sonologists. Fat necrosis may result from accidental trauma, after surgery or radiation therapy. The sonographic features of fat necrosis are varied and depend on the degree of fibrosis.
Axillary lymphadenopathy in normal breast on USG is an incidental finding. USG may some extent differentiate between benign and metastatic lymph nodes by presence of a fatty hilum which is absent in metastatic lymph nodes.

\section{CONCLUSION}

Sonomammography is a very dynamic and powerful tool for the evaluation of breast lumps. It very well differentiates between solid and cystic masses. It is good for assessment in non-palpable masses, assesses disease spread and aging, metastatic spread, USG guided FNAC, cheaper, having no radiation, good for assessing vascularity of lesion. Hence USG should be used as the primary investigation or in conjunction with X-ray mammography for the evaluation and characterization of the breast lumps.

\section{REFERENCES}

1. Maturo VG, Zusmer NR, Gilson AJ, Smoak WM, Janowitz WR, Bear BE, Goddard J, Dick DE. Ultrasound of the whole breast utilizing a dedicated automated breast scanner. Radiology. $1980 ; 137(2): 457-63$.

2. Guyer PB, Dewberry KC. Ultrasound of the breast in the symptomatic and x-ray dense breast. Clin Radiology. 1984; 36:69-76.

3. Smallwood J, Khong Y, Boyd A, Guyer P, Herbert A, Cooke T, Taylor I. Assessment of a scoring scheme for the preoperative diagnosis of breast lumps. Ann R Coll Surg Engl. 1984; 66(4): 267- 269

4. Stavros AT, Thickman D, Rapp CL, Dennis MA, Parker SH, Sisney GA. Solid breast nodules: use of sonography to distinguish between benign and malignant lesions. Radiology 1995; 196:123-134.

5. Baker JA, Kornguth PJ, Soo MS, Walsh R, Mengoni P. Sonography of solid breast lesions: observer variability of lesion description and assessment. AJR. 1999; 172:1621-1625.

6. Sklair-Levy M, Sella T, Alweiss T, Craciun I, Libson E, Mally B. Incidence and management of complex fibroadenomas. AJR Am J Roentgenol. 2008;190 (1):214-218.

7. Rahbar G, Sie AC, Hansen GC, Prince JS, Melany ML, Reynolds HE, Jackson VP, Sayre JW, Bassett LW. Benign versus malignant solid breast masses: US differentiation. Radiology. 1999; 213 (3):889-894.

8. Basset LW. Imaging of breast masses. Radiol Clin North Am. 2000;38: 669-91.

9. Mendelson EB, Berg WA, Merritt CR. Toward a standardized breast ultrasound lexicon, BI-RADS: ultra- sound. Semin Roentgenol. 2001; 36:217-225. 